\title{
Enhance the Interaction of Students with Learning Difficulties by Implementing a Social Coexistence Programme in Greek Primary Schools
}

\author{
Ilias Vasileiadis ${ }^{1, *}$, Spyros Koutras $^{2}$, Ioanna Dimitriadou ${ }^{3}$, Ioanna Gripsiou $^{4}$ \\ ${ }^{1}$ Department of Primary Education, University of Thessaly, Volos, 38221, Greece \\ ${ }^{2}$ Department of Speech and Hearing Sciences, Queen Margaret University, Edinburgh, EH21 6UU, United Kingdom \\ ${ }^{3}$ Department of Educational \& Social Policy, University of Macedonia, Thessaloniki, 54636, Greece \\ ${ }^{4}$ School of Psychology, Faculty of Philosophy, Aristotle University of Thessaloniki, Thessaloniki, 4124, Greece
}

Received June 30, 2021; Revised August 15, 2021; Accepted August 30, 2021

\section{Cite This Paper in the following Citation Styles}

(a): [1] Ilias Vasileiadis, Spyros Koutras, Ioanna Dimitriadou, Ioanna Gripsiou, "Enhance the Interaction of Students with Learning Difficulties by Implementing a Social Coexistence Programme in Greek Primary Schools," Universal Journal of Educational Research, Vol. 9, No. 9, pp. 1713 - 1723, 2021. DOI: 10.13189/ujer.2021.090911.

(b): Ilias Vasileiadis, Spyros Koutras, Ioanna Dimitriadou, Ioanna Gripsiou (2021). Enhance the Interaction of Students with Learning Difficulties by Implementing a Social Coexistence Programme in Greek Primary Schools. Universal Journal of Educational Research, 9(9), 1713 - 1723. DOI: 10.13189/ujer.2021.090911.

Copyright $\bigcirc 2021$ by authors, all rights reserved. Authors agree that this article remains permanently open access under the terms of the Creative Commons Attribution License 4.0 International License

\begin{abstract}
Increasing social and emotional development of primary school students with learning difficulties promotes equal participation in educational processes at all levels of their education. Social coexistence programmes at all school levels empower all students both emotionally and socially by promoting solidarity and creatively enhancing the learning environment. The aim of this research was for the students with learning difficulties and the teachers to evaluate a social coexistence programme implemented in a Greek Primary School. The program involved 22 students in a 4th-grade class, 4 of whom had been diagnosed with learning difficulties, and 4 members who are scientific and teaching staff of the school. In order to evaluate the actions of the programme, the multimethodological approach was applied by using a sociometric tool and a logbook, and by conducting semi-structured interviews. The research results showed that the social interaction of students with learning disabilities with their peers increased significantly after the completion of our intervention. The development of a collaborative culture in school was cited as a decisive factor for the effective implementation of social coexistence programmes by the participating adults. The results are discussed in the context of implementing similar interventions in more classes by having more students and members of the
\end{abstract}

teaching staff participating as well.

Keywords Social Interaction, Social Coexistence Programmes, Learning Difficulties

\section{Introduction}

The quality of social interaction of students is directly related to the broader educational policy implemented for their educational and mental development. Over the last 20 years, promoting social inclusion policies (with different approaches and results from country to country) has increased the social interactions of students with learning and accompanying emotional and social difficulties both within schools and in general [1].

However, research data show that it is not enough for students with learning difficulties just to coexist with their classmates in school in order to develop benefits and promote their social and emotional development [2]. Without systematic intervention, children without learning difficulties tend to interact with students who have the same abilities as them rather than with those who have special educational needs [3]. Subsequently, students with learning difficulties who do not participate in integration 
processes find it particularly difficult to participate in team games and group activities. Usually, these students are individually taught for several hours every day, so there is no possibility of systematic interaction with their classmates [4]. Therefore, students with learning difficulties do not actively participate in social activities at school, mainly due to the lack of opportunities to interact with peers [5].

Also, the interpersonal relationships of students with learning difficulties are more superficial and less stable [6]. Although coexistence and proximity are necessary conditions for developing meaningful social relationships and interactions, they are often insufficient. Koster [7] and colleagues report that $25 \%$ of the students with special educational needs experience difficulties in forming social relationships with their peers, while for students with typical growth this figure is at $8 \%$. The limited social participation and the difficulties in social relations during childhood may give these children additional hard time managing the school day-to-day routine (e.g., aggression, anxiety) [8] and difficulties in adapting later in their adulthood [9].

Rose Fletcher \& Goodwin [10] investigated the levels of participation of students with learning difficulties in school everyday life (breaks, sports activities holidays) and highlighted the need to systematically promote these students' interaction with peers in all aspects of school life. Following organised interventions, when practices that promote interaction through experiential learning are established, teachers usually see an improvement in such students' social behaviour and an increase in their selfesteem. The above researchers conclude that the processes of participation in school should be taken seriously by any school that aspires to promote the social and emotional empowerment of all its students.

In addition, there are variations in the type of games, as the social game of students with special educational needs is less sophisticated than their classmates of the same chronological and developmental age [11]. The above conclusions are confirmed by Ramsey [12] who states that children with severe learning difficulties do not participate and are left behind when the game becomes more complex and requires more social and cognitive skills. Thus, being separated and isolated from group processes, students with special educational needs have difficulties in establishing close relationships while they express - often dominant - frustration and dissatisfaction about their already existing relationships with peers, as they consider they are often required to manage unacceptable behaviours [13].

Because of the above, students with learning difficulties interact less with their peers and are guided much more by adults which results in strengthening their relationships of dependence on the teaching staff. The relationships they develop are prone to conflict, and the students themselves exhibit aggressive and negative verbal and nonverbal behaviour, or they are disruptive or withdrawn. Because of these behaviours, these students are actively rejected by their classmates [14].

Therefore, if students are simply left in an unstructured context of coexistence and communication, such as game or break time, then developing positive attitudes towards students with learning difficulties is at a low level. For example, in school breaks, where there is no provision for organised socialisation activities, children with special educational needs tend to isolate themselves and be mocked at. When interaction takes place based on a structured plan which involves collaborative learning, working in a group and organised games, the outcome is different as the social interaction strengthen [15]. January, Casey \& Paulson [5] argue that only after participating in structured coexistence programmes which promote the assumption of responsibility by each participating student, which have as a principle the parity of participants in responsibilities and learning opportunities, and which do not promote pity for a peer, students with difficulties are accepted in the long term at school. Finally, the collaboration and daily coexistence of all students allows for emotional engagement and skill acquisition. Negotiation, practice, and repetition enable students gradually to solve everyday school problems on their own.

\section{Materials and Methods}

\subsection{Purpose of the Survey}

The research aimed to investigate the interpersonal and social relationships of students with learning difficulties towards their peers. In addition, to examining whether there are changes in the interpersonal and social relationships of students with learning difficulties towards their peers after participating in a coexistence programme.

The individual objectives of the research were to investigate:

- Whether there have been changes in the social interaction of children with learning difficulties towards their peers, following the implementation of the coexistence programme. If so, what changes they were.

- What the social interaction of children with learning difficulties with their peers was while implementing the programme.

Based on the individual objectives, the following research questions regarding students with learning difficulties were formulated:

- Do they develop social interactions with their classmates in everyday school life? (1st research question)

- Is there a difference in their social interactions after implementing the social coexistence programme? (2nd research question) 
- Who do they interact with in the school context and how? To what extent after implementing the social coexistence programme? (3rd research question)

\subsection{Survey Methodology}

In the present research, the poly-methodological approach was considered necessary in order to allow for more thorough study and control. Thus, the shortcomings of each individual methodology are more effectively addressed. Subsequently, methodological triangulation is associated with verifying the same results and research findings with many, different, and often competing methods. Finally, the choice of the poly-methodological approach was dictated by our effort to make different methods complement each other. Apart from complementing, the different methods reinforce each other by answering the same research questions, thus verifying the correctness of the research findings [16]. The research tools used included semi-structured interviews (Phases I and III of the research), logbook keeping (Phase II), and sociometric evaluation (Phases I and III). The above research tools are provided by respective intervention programmes [17].

\subsection{Participants}

The survey involved 22 fourth-grade students, averaging 9.4 years old, of a public primary school in northern Greece, 4 of whom were diagnosed with generalised learning difficulties by the relevant educational service. With the consent of their parents, the students participated in the social coexistence programme during the school year 2018-2019. The profile of the participating students was homogeneous, the ratio of boys to girls consistent with the ratio found in Greek primary schools, and their main school experiences were common since no student had switched schools.

In addition, the class teacher, the physical education teacher, the psychologist and the special education teacher of the school also participated in the social coexistence team. The programme consisted of 3 Phases: Phase I before the start of the programme, when the preparation was being carried out; Phase II - in the course of implementing the programme; and Phase III - after the completion of the coexistence programme. The social coexistence programme started in November 2018 and was completed in May 2019, which lasted for 6 months in total. Data collection for Phase I was completed in January, for Phase II in May and for Phase III in June.

\subsection{Description of the Social Coexistence Programme}

The goals of the team were for all the participating students (a) to feel better in relation to themselves, to form a positive self-perception and self-confidence; (b) to learn how to regulate their experiences from their contact with others on their own, without the moderators intervening, in order to coexist harmoniously with everyone (in other words, to become familiar with the free expression of feelings and thoughts); (c) to learn how to accept different opinions, to become sensitive and open to the "truth" of the other, to state clearly their desires, limits and feelings; (d) to participate and cooperate with ease.

The team met 16 times on predetermined days for two teaching hours each time, during which the participants dealt through experiential exercises with issues of communication, interpersonal relationships, and everyday issues of school and social life.

At the beginning of the school year, these 22 students formed the "coexistence team". Meetings were held in a specially designed classroom, the self-regulation room. In this 8 -by- $4.5 \mathrm{~m}$. room, foam was placed on the walls, the floor was relatively soft with carpeting and tarpaulin, and there were large gym mattresses and pillows of various sizes. Through the lack of specific games that usually guide the activity, this was done in order to prioritise the promotion of relationships, communication and physical contact. The school psychologist, along with the accompaniment of the teachers, coordinated the team.

During meetings, the method followed was based on Michel Lobrot's non-directional intervention (NDI) [18]. The stages of each meeting were as follows: Initially, there was a warm-up exercise for the students to become active in relation to what would follow. Then the "main" exercise took place which usually applied activities related to physical and artistic expression. Verbal exercises were avoided so that everyone could equally participate with ease. Then, the team would split into small groups of three or four, followed by a discussion of how each person felt or what thoughts arose from a particular exercise. Small groups served to facilitate those who had a hard time speaking in the full-attendance session that followed, as one finds it usually easier to speak in front of a not very large group. Finally, the session with full attendance came, that is, gathering in a single group, during which a representative from each small one briefly presented what had been said before. When there was time, he could follow a second exercise in the same way. The meeting concluded with the discussions taking place with full attendance.

It is important to point out that neither the beginning nor the conclusion of each of the above stages were strictly predetermined. There was always room for the course of the meeting to change, taking into account what the participants wanted. The boundaries were flexible enough so as the team would feel pleasure rather than pressure. Emphasis was given on forming the conditions that promote communication and participation. For this reason, the team members sat always (a) in a circle; and (b) in random positions. We provided so that not all the boys and the girls were gathered because that would form pseudo sub-teams resulting in complicating communication between the participants. Both the method and the techniques chosen favoured the energy and 
equality of the members.

\subsection{Data Collection}

Sociometric test

For the needs of this research, overall assessments were chosen as the most suitable for investigating and comparing each student with learning difficulties desire for social interaction with their classmates before and after the intervention. The sociometric test was conducted on the four students with learning difficulties 2 times (Phases I and III of the programme): (a) 3 weeks after the beginning of the intervention, to ensure that the students are familiar with the team principles and approach; and (b) 1 week after the completion of the intervention, in order to check whether there are differences in the assessments of the students before and after the intervention. The test was taken in the presence of the class teacher and the psychologist in the classroom so that the students would feel familiar with the space. For ethics, the test was given to the remaining 18 students as well.

Each student was given an impromptu booklet. The first page included the instructions for filling. However, it was considered appropriate for the teacher to explain the instructions orally due to the cognitive difficulties of the students so as to fully ensure the reliability and validity of the test. On each page, there was the question "I would like to be in the same company with..." followed by a student's name and photo. On the same page, students were asked to circle their choice on a 3-level Likert scale by choosing one of the options "Yes, I would", "I don't mind", "No, I wouldn't". Next to each choice was the corresponding picture of a face with a cheerful, neutral, or sad expression. The names of the students in the booklet were sorted alphabetically. On each page students therefore answered the same question for each student participated in the programme.

The choices regarding the question (the scale, the wording, and the way it was displayed) were considered appropriate for investigating changes in the mood for social interaction according to students' age and learning capabilities, the intervention framework, and the international literature [7]. In this way, it was ensured that the test requirements were in line with the students' abilities.

\section{Semi-structured interviews}

For the needs of this research, semi-structured interviews were conducted by the 3 teachers who participated in the programme and with the 18 students who are not diagnosed with learning difficulties. For ethics, interviews were conducted with all 4 students with learning difficulties as well, but the material has not been taken into account in this research. The interviews were given to the psychologist who was coordinating the intervention programme. The thematic axes and questions of the interview guide were formulated in line to the potential and difficulties of the students based on the general objective, i.e., to explore the views of the people involved regarding whether there is a change to be found in the interpersonal and social relations of students with learning difficulties after the completion of the social coexistence programme.

Apart from demographics, the main thematic axis which the questions in Phase I (prior to the programme) and Phase II (after the programme) were based on was the following:

Social interaction with peers: The questions were aimed at seeking information on what the forms of social activities developed by each student with learning disabilities are, their level of participation and their role in social activities. In addition, each student's potential initiatives for social contact were investigated as well as the attitude of the peers towards these initiatives for interaction. Finally, in Phase III, any changes in the social interaction of students with difficulties was investigated as well as the reasons for these changes [19].

The interviews were conducted in a teacher's area of the school in the first and last two weeks of the programme. All interviews were transcribed with the consent of the participants. The average length of each interview was 28 minutes. During transcription, the material was transcribed verbatim, and every item that could describe the behaviour of the respondent was noted. The interviews with the students were conducted individually, in the school classroom, during the same period and with the same thematic axes adapted to the possibilities and difficulties of the students. The special educator was also present.

\section{Logbook keeping}

From the beginning of the intervention programme (Phase II), the 4 adult participants we asked to keep a pedagogical logbook with the activities in which they participated. The recordings were focused on (a) capturing and recording the social-emotional atmosphere during the activities through the manifestations of students' behaviour; and (b) reflecting on themselves aiming at self-awareness and understanding the planning and management of educational activities [20].

Finally, in order to ensure reliability and validity, the procedures below within the framework of the poly-methodological approach were followed: For reliability, we applied: (a) the criterion of prolonged engagement - since the participating teachers teach in this particular school for several years; (b) the member checks criterion - because every documented and transcribed research material was given for review; and (c) the tripartite intersection - since each variable was tested with more than one research tool. For validity, we applied: (a) transferability - the entire course of the research was described in detail; (b) dependability - since the details of the methodology, the confidentiality statements (personal 
archive of the researcher) and the work plan (completed file) were kept and are available; and (c) confirmability because the interview guide, texts and files along with the researcher's interview notes, the booklets used for the sociometric test, the coding system, and the statistical analyses were kept and are available as well [21].

\section{Results}

The quantitative analysis of the sociometric test was done using SPSS (version 21). Subsequently, the halfstructured interviews and logbook analysis was qualitative, and the method of qualitative content analysis was used.

\section{Quantitative Data Analysis}

The quantitative analyses concern the data collected through the sociometric tool for the 4 participating students with learning difficulties in Phases I and III (before the beginning of the intervention and immediately after its completion). The sociometric measurement attempted to investigate whether classmates are willing to interact with their peers with learning difficulties. In the responses given by students with disabilities for each student who participated in the programme, the nonparametric Wilcoxon test was used. It was chosen because the sample $\mathrm{N}$ of the survey is not so large (less than 30) meaning that the normality condition is not clearly guaranteed. The answers to the question "I would like to be in the same company as..." were made on a three-level scale for each participating student and rated as follows: (a) for each answer "Yes, I would", 3 points were given; (b) for each answer "It doesn't bother me", 2 points; and (c) for each answer "No, I wouldn't", 1 point was given. Thus, the maximum score that a student with learning difficulties could receive was 54 (18 classmates without learning difficulties $\mathrm{x} 3)$ and the minimum 18 (18 classmates without learning difficulties $\mathrm{x} 1$ ).

The results of the analyses were: 1 st student (Jim) z (18) $=-4.00, \mathrm{p}<.001,2$ nd student $($ Kate $) \mathrm{z}(18)=-4.12, \mathrm{p}$ $=.001,3$ rd student $($ Jack $) \mathrm{z}(18)=-4.06, \mathrm{p}=.001,4$ th student (Paul) z $(18)=-3.96, p<.001$, while averages and standard deviations are given in Tables 1A and 1B.

Table 1. Average and standard deviation of acceptance rates by peers in the Wilcoxon test for 2 students with learning difficulties, before and after the intervention.

\begin{tabular}{ccccc}
\hline & JIM & KATE & JACK & PAUL \\
Acceptance & N=19 & N=19 & N=19 & N=19 \\
& Avg. & Avg. & Avg. & Avg. \\
& SD & SD & SD & SD \\
\hline \multirow{2}{*}{ Before } & 1.11 & \multirow{2}{*}{1.190 .23} & 1.11 & 1.11 \\
& 0.32 & & 0.32 & 0.32 \\
After & 2.84 & 2.560 .32 & 2.880 .32 & 2.74 \\
& 0.38 & & & 0.45 \\
\hline
\end{tabular}

The study of the results shows that there is statistical significance for every student with learning difficulties. The desire of these students to interact with their peers who participated in the actions, after the end of the social coexistence programme is different. The statistically significant increase in the average values of each student with learning difficulties during iterative measurement (Graph 1) highlights the increase in the desire for interaction of the above students with their participating peers. Therefore, the analyses show that, before the implementation of the social coexistence programme (Phase I) in school everyday life, students with learning difficulties did not develop adequate social interactions with their classmates (1st research question). Also, after implementing and completing the intervention (Phase III), there is an increase in social interactions of students with learning difficulties who appear to be more accepted by their peers ( 2 nd research question).

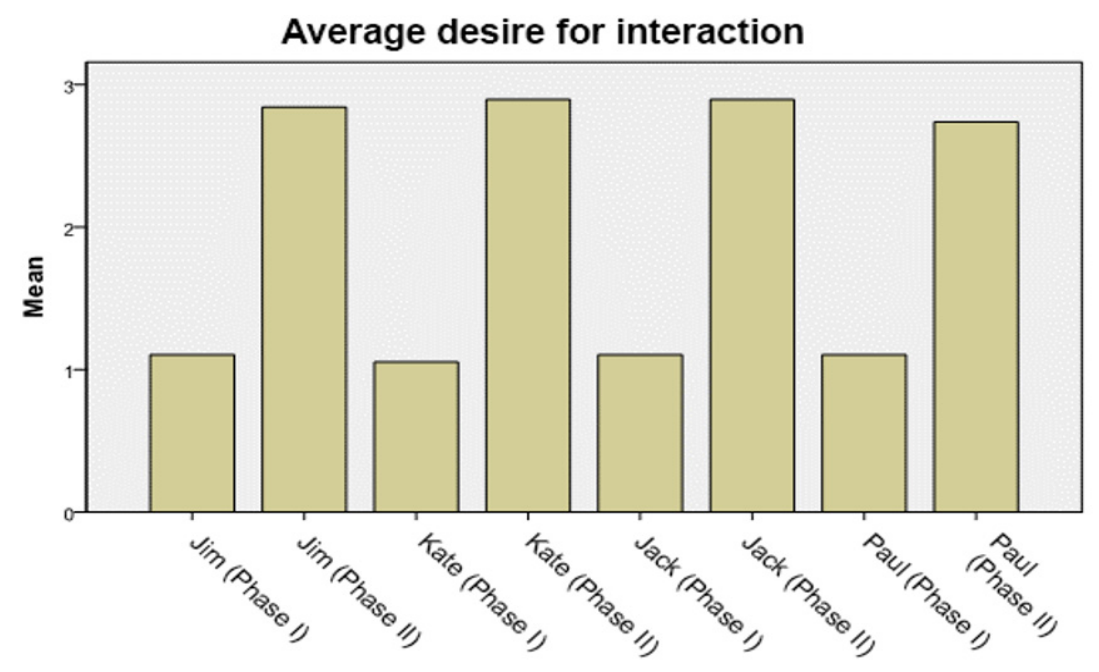

Figure 1. Averages of the desire for interaction with the 4 students with learning difficulties by their peers, before and after the intervention 
Table 2. Social interaction with peers: Inductive system of categories for interviews and logbook

\begin{tabular}{|c|c|c|c|}
\hline Phases & $\begin{array}{c}\text { Phase I (before the } \\
\text { implementation of the } \\
\text { programme) }\end{array}$ & $\begin{array}{c}\text { Phase II (during the } \\
\text { implementation of the } \\
\text { programme) }\end{array}$ & $\begin{array}{c}\text { Phase III (after the } \\
\text { implementation of the } \\
\text { programme) }\end{array}$ \\
\hline Categories & Subcategories & Subcategories & \\
\hline $\begin{array}{c}\text { 1. Participation in social } \\
\text { activities }\end{array}$ & $\begin{array}{l}\text { 1.1. Limited participation } \\
\text { 1.2. Form of participation }\end{array}$ & $\begin{array}{c}\text { 1.1. Increase of participation } \\
\text { 1.2. Form of participation }\end{array}$ & \\
\hline 2. Initiatives for social contact & $\begin{array}{c}\text { 2.1. Initiatives for social contact } \\
\text { 2.2. Reasons for the lack of } \\
\text { initiatives for social contact } \\
\text { social contact }\end{array}$ & $\begin{array}{c}\text { 2.1. Support of the initiative for } \\
\text { student's initiative for social } \\
\text { contact }\end{array}$ & \\
\hline $\begin{array}{c}\text { 3. Considerations and } \\
\text { objectives for social } \\
\text { interaction }\end{array}$ & \multicolumn{2}{|l}{} \\
\hline
\end{tabular}

\section{Qualitative Data Analysis}

The analysis of the qualitative data was done with the help of the semi-structured interviews (Phases I and III) and the logbook (Phase II). The inductive system of categories on which the analysis was based can be seen in Table 2.

Below, one can see the findings of qualitative content analysis by category and group (i.e., educational staff, students) of participants in all Phases (before, during, and after the intervention programme).

\section{Phase I - Before the Intervention Programme}

\section{Participation in social activities}

\subsection{Limited participation}

Students with learning difficulties did not actively participate in any social or group activity because of their slow pace and difficulties in understanding the rules. They found it very difficult to communicate, and they usually annoyed their peers.

"No, I haven't seen him play in team games, certainly not in my class nor during breaks... Always alone, in his different, odd pace, no contact with others" (physical education teacher on Jim).

"No, we're not playing with Kate... She's ruining our game and always crying... We don't want her" (Barbara, classmate, on Kate).

\subsection{Form of participation}

In the social conditions in which the students of the class were forced to interact, their contact was fragmentary, not lasting, and very problematic. Students with learning difficulties perceive their peers as indifferent towards them.

"Sir, I tell Jim (classmate) to come and play but he doesn't want to, he doesn't go with the others [= classmates]" (Tom, classmate, on Jim).

"No, in my class, which is more relaxed, I do not notice any of them [one of the 4 students with learning difficulties] working smoothly, systematically with none -much nagging" (physical education teacher).

\section{Initiatives for social contact}

\subsection{Absence of initiative for social contact}

Those involved felt that students with learning difficulties did not take initiatives for social contact either because they did not know the appropriate way or because they did not want to.

"I don't want, I don't want, not with them, they're bad guys" (Sam, classmate, on Jim and Paul).

"She doesn't take initiative for social contact either... She has no contact but the integration department. She's isolated" (Special education teacher on Kate).

\subsection{Reasons for the lack of initiative for social contact}

Many of the adults involved have the attributes that students with learning difficulties did not take initiative when communicating with peers and adults was found to be difficult. Some of the respondents considered that the difficulties in social contact for students with learning difficulties resulted also from the fact that school and the society often treat learning difficulties as a problem, which leads to the isolation and restriction of the above students.

"But how would they interact when no one lof the students with learning difficulties] can communicate with ease? Their classmates cannot understand them" (Physical education teacher).

"Jim doesn't take any initiative... They don't want him very much - there isn't the appropriate treatment towards students with difficulties, everyone in practice avoids them; they think they have something, like a disease that sticks, and we all have responsibility for, both teachers and parents" (class teacher on Jim).

3. Considerations and objectives for social interaction

Respondents are optimistic that, with the 
implementation of this programme, the social interaction of these students will improve. Some have focused on the cooperation of everyone involved in achieving this goal.

"We will show the way with our persevere and systematic work that there are possibilities for the cognitive and social development of all our students" (class teacher).

"Yes, yes, I want to play with him... As long as he doesn't spoil the game (Nick, classmate, on Jack).

\section{Phase II - During the Intervention Programme}

1. Participation in social activities

\subsection{Increase of participation}

From the first weeks of the programme, participants report that they see an increase in the participation of students with learning difficulties in collective and social activities both in class and during breaks.

"Increasing interaction is important both in the classroom and during the breaks for all of them [= the students with learning disabilities]" (Special education teacher).

"It is striking that these students [with learning difficulties] are eager to participate in all activities. During breaktime supervision, I notice that other students, especially girls, are getting closer."

\subsection{Form of participation}

All those involved in the programme point out that the social interaction of students with learning difficulties is promoted in structured activities in case they are judged by the above students as understandable and pleasant.

"I think that now [ $=5$ th week of the intervention] we have adapted our programme to our students' capabilities, and they actively participate" (special education teacher).

"I'm looking for what's changed [in the 6th week of intervention] I conclude: we are more organised, there is a plan, and we, teachers, follow it first " (class teacher).

2. Initiatives for social contact

\subsection{Support of the initiative for social contact}

The majority of the teaching staff state that during the programme, the initiatives of students with difficulties to interact with their peers are intensified.

"The intervention is systematic, and the transitions from activity to activity enable all students to ask, suggest, and communicate" (physical education teacher).

"Initiatives are growing for all students; impressively now [ = 4th week of intervention] (class teacher).
2.2. Response of others to the student's initiative for social contact

Those involved believe that, despite the difficulties, the mood for interaction between all students gradually increases, and the common ground for communication between them is more obvious.

"It seems that they are slowly making, like every group of children, their own code in the game. I consider it very important, the essence of our intervention" (class teacher).

"Now, they work as a group, as a class; they try to communicate" (physical education teacher).

3. Considerations for social interaction

Participants recorded a shift in their assessments of social interaction. While, initially, there were reservations about the possibility of enhancing the social interaction of students with learning difficulties through the intervention programme, they gradually reported that these students were becoming more social.

"I wasn't optimistic, but now I see the difference; he plays with the rest of the class" (physical education teacher on Jim).

"The change is great this week $[=8$ th week]. They were playing in the yard without our guidance" (class teacher).

\section{Phase III - After the Intervention Programme}

1. Level of participation and role in social activities

All students with learning disabilities now participate in almost all social activities both within and outside the school.

"He participates, not actively of course, but with pleasure... Don't forget he also participated in the school play." (Special education teacher on Jim).

"No, now we want her... She's doesn't bother us in the team and plays with us (Antonia, classmate, on Kate).

\section{Initiatives for social contact}

Students with learning difficulties now take initiatives, greet and smile at their peers, ask other children to play together, discuss issues that interest them, etc.

"Now we know that he wants to contact, he is showing it to us; He asks for it both verbally and not, and we also support him to" (class teacher for Jack).

"Yes, he greets us; he is not a savage; we want him in company..." (Thanos, classmate, on Paul).

\section{Considerations for Social Interaction}

In the view of the participants, a culture of cooperation 
developed between all students. This culture allows all students to develop a common ground for communication.

"To be honest, now we've gotten to know each other better, cooperation is now genuine" (class teacher).

"We became a team with difficulties and bad, but we worked together without any compunction and you know why? Because we spoke the same language, we had a guide, a philosophy and a method, our views changed; We stopped seeing who is the best and who isn't and we focused on how everyone can learn in the classroom. The same thing happens with the students; They have their own communication, their jokes. All together" (special education teacher).

The above findings of qualitative analyses confirm the 1 st and 2 nd research questions. In particular, students with learning difficulties showed that before the beginning of the intervention programme, they had not developed social interactions with their classmates in school life (1st research question). On the contrary, it appears that there is a difference in their social interactions after the implementation of the social coexistence programme, which are recorded as more positive (2nd research question). In addition, it is shown that before the beginning of the intervention, students with learning difficulties interacted mainly with the educational staff during their time at school, while their social contacts with peers were limited. However, after the intervention, reports on the social interaction of students with learning difficulties differ considerably. It is reflected that they interact systematically mainly in structured activities that promote cooperation and mutual assistance with their classmates during school hours. These changes are attributed to the prevailing school culture that enhances non-competitive relationships among students (3rd research question).

\section{Discussion}

The quantitative results and the qualitative analysis of the data revealed a change in the interpersonal and social relations of students with learning difficulties with peers during and after the social coexistence programme. The above findings answer the research questions and converge with the findings that have emerged from the evaluation of similar coexistence programmes with students with learning difficulties.

More specifically, it was found that before the programme, students with learning difficulties had not developed stable social interactions with their classmates in school everyday life (1st research question). The above finding is confirmed by relevant research. Students with learning difficulties have a seriously hard time developing social relations during the period of schooling [22]. Symptoms of loneliness, low self-esteem, and inadequate social adaptation [23]. These students lag in common education experiences as well. Particularly, in many cases, they attend tailored curricula and are absent in most of the teaching in the classroom due to educational planning. However, even when they are present, there is no physical proximity to their peers [24]. As a result, students with learning difficulties lose the opportunity to interact with peers, engage in social relationships, and, learn and practice their social skills with them [25]. In addition, it is confirmed that students with learning difficulties are lagging in social negotiating and understanding skills, among others. Thus, they have limited ability to project their pursuits towards others and assert their rights. They also find it difficult to take initiatives, establish relationships, cooperate, and resolve various conflict situations [26].

Subsequently, the results of this research revealed that there is a difference in social interactions of students with learning difficulties after the implementation of the social coexistence programme (2nd research question). Furthermore, it is noted that there is a significant improvement in the interaction of students with learning difficulties who participated with their peers as well as an increase in their participation in group activities by taking initiatives to communicate with their peers after the completion of the programme. The above results are reinforced by similar research findings.

More specifically, a survey by Waldron, Leskey and Pacchiano [27] using self-referential questions highlighted, among other things, the increase in initiatives for social interaction by students with special educational needs, following participation in a social inclusion programme aimed at developing social skills and the joint attendance of students with and without learning difficulties. According to the teachers, after the programme, initiatives for interaction of most students with learning difficulties increased, and their cooperation with peers in classroom significantly improved. Still, the behaviour of most students with learning difficulties did not differ from that of the rest of their classmates. Finally, the participating teachers stated that students with special educational needs developed interpersonal relationships with both students with and without special educational needs. Therefore, their presence in the classroom contributed to the improvement of their social relations.

In addition, the results of this research revealed significant difference regarding the communication and active participation of students with learning difficulties in team activities after the completion of the intervention. According to Ginevra et al. [28], coexistence programmes enable all participating students to gain greater levels of active participation in school everyday life, develop communication with each other, implement strategies to promote cooperation, increase social interactions, and reduce unwanted behaviours.

Moreover, research data show that after the programme, students with learning difficulties interact more systematically with their peers in school, mainly in 
structured activities and more in cases where the prevailing school climate promotes cooperation between children and is not perceived by students as competitive (3rd research question).

As is found by qualitative and quantitative analyses, the participation of students in social coexistence programmes results in authentic relationships between peers rather than unequal and caring ones. All students are given the opportunity to contact with each peer as a separate entity and not with the qualities that characterise some of them (e.g., lazy, slow-witted, etc.). On the contrary, when students with learning difficulties are treated in schools as a sub-team with specific characteristics, they have much less acceptance because it easily leads to polarisation between the inner teams, for example, among students with learning difficulties and those without who performance well [29]. More generally, the participation of students with learning difficulties in social inclusion programmes, where organised play dominates, leads to more positive interactions with peers and improved attitudes towards school and learning [30]. Coexistence programmes enable all participating students to gain greater levels of active participation in school life, implement strategies to promote cooperation, increase their social interactions, reduce their unwanted behaviours, give frequent feedback to their classmates as well as enhance their social skills [31].

In addition, the majority of the participating teachers in this research considered that the prevailing culture in each school is a key factor in shaping and promoting the social inclusion of students with difficulties at local and intracommunity level. The culture of inclusive education promotes the equal participation of students in school everyday life and leads to their inclusion in both the school and the wider social context, while it is necessary to apply specific methodological principles by all involved in educational processes in order to consolidate it $[32,33]$. However, according to the views expressed by the participants, the prevailing school culture in Greece often reinforcesindividual character of their participation in educational processes, the disapproval of cooperation between them, their exclusive orientation to academic performance, their discrimination based on school performance and values, and the claim by the students of the desired assessment and acceptance by the teacher [34]. The above values promote competition among peers and leave no room for authentic and equal social relations between competent and incompetent students to develop. In other words, they prevent the "code of peers" to be developed that facilitates social interaction between students $[35,36]$.

\section{Limitations}

When interpreting the results, it is essential to take into account the methodological limitations of the present research. First, the sample of the survey was small, as it involved only 4 teachers and 22 students. Secondly, it was not possible to compare the views and assessments of teachers and students with those of another school where the social coexistence programme was not implemented. Thirdly, another limitation is that no follow-up after a long period of time could take place and the research data are compared in order to investigate whether there were any changes in the results. Additionally, a weakness of the reliability of the research can be considered, namely the assessments of the others involved in the educational process (teachers, managers, parents) were not thoroughly investigated. Finally, the further application of a multimethodological approach would allow to draw more quantitative and qualitative data and therefore lead to safer conclusions through developing and applying naturalistic observation.

\section{Conclusions}

From the limitations, based on the conclusions that were drawn from this research, prospects for further research with particular theoretical and research interest emerge. Primarily, it would be interesting to apply the research to a larger sample of participants as well as to investigate the specific programmes over a longer period of one school year in order to compare and draw safer conclusions regarding the participants' assessments. In addition, it seems that it would be important to examine the possibilities of investigating and comparing the views of administration officials who have long been responsible for shaping the educational policy regarding students with learning difficulties. Finally, by more broadly approaching the processes of equal participation of students with learning difficulties in educational processes, it would be important to explore the views of such students themselves, about the way they perceive and experience the prevailing educational policy.

The research data showed an increase in social interaction between students of typical development and their classmates with learning difficulties who took part in the coexistence programme. In detail, the quantitative data showed that the social interaction of students with learning difficulties increased significantly compared to the Phase I measurements. The analysis of the qualitative data showed that the conversion and change of behaviour of peers was attributed by those involved to the feeling developed during their participation in the coexistence programme that they belong to the same age group, in the same school and that they share common experiences. These testimonials highlight how participating students were energised and socially supported their peers with learning difficulties. 


\section{Acknowledgements}

We would like to extend great thanks to all participants in the research process, students and teachers, as well as the administrative staff of the school where the intervention took place.

\section{REFERENCES}

[1] M. Israelashvili, E. Menesini, \& M. Al-Yagon, Introduction to the special issue on Prevention and Social-Emotional Development in Childhood and Adolescence, European Journal of Developmental Psychology, Vol. 17, No. 6, 787-807, 2020,https://doi.org/10.1080/17405629.2020.183 0273

[2] S. R. Forness \& K. A. Kavale, Treating social skill deficits in children with learning disabilities: A meta-analysis of the research, Learning Disability Quarterly, Vol. 19, No. 1, 2-13, 1996 https://doi.org/10.2307/1511048

[3] S. L. Greenham, Learning disabilities and psychosocial adjustment: A critical review, Child neuropsychology, Vol. 5, No. 3, 171-196, 1999, https://doi.org/10.1076/chin.5.3.1 71.7335

[4] R. P.Corcoran, A. C. Cheung, E. Kim \& C. Xie, Effective universal school-based social and emotional learning programs for improving academic achievement: A systematic review and meta-analysis of 50 years of research, Educational Research Review, Vol. 25, 56-72, 2018, https://doi.org/10.1016/j.edurev.2017.12.001

[5] A. M. January, R. J. Casey, D. Paulson, A meta-analysis of classroom-wide interventions to build social skills: Do they work?, School Psychology Review, Vol. 40, No. 2, 242-256, 2011, https://doi.org/10.1080/02796015.2011.12087715

[6] A. Vlachou, Struggles for inclusive education: An ethnographic study, Buckingham: Open University Press, 1997

[7] M. Koster, H. Nakken, S. J. Pijl \& E. van Houten, Being part of the peer group: A literature study focusing on the social dimension of inclusion in education, International Journal of Inclusive Education, Vol. 13, No. 2, 117-140, 1999 https://doi.org/10.1080/13603110701284680

[8] S. Pavri, Introduction: School-based interventions to promote social and emotional competence in students with reading difficulties, Reading \& Writing Quarterly, Vol. 22, No. 2, 99-101, 2006, https://doi.org/10.1080/10573560500 242176

[9] P. Caldarella \& K. W. Merrell, Common dimensions of social skills of children and adolescents: A taxonomy of positive behaviors, School Psychology Review, Vol. 26, No. 2, 264-278, 1997, https://doi.org/10.1080/02796015.1997. 12085865

[10] R. Rose, W. Fletcher \& G. Goodwin, Pupils with severe learning difficulties as personal target setters, British Journal of Special Education, Vol. 26, No. 4, 206-212, 1999 , https://doi.org/10.1111/1467-8527.00140
[11] K. W. Merrell, \& G. Gimpel, Social skills of children and adolescents: Conceptualization, assessment, treatment, London: Psychology Press, 2014.

[12] G.P. Ramsey, Teaching and Learning in a Diverse World. Multicultural. Education for Young Children, New York: Teachers College Press, 2004.

[13] H. L. Swanson \& S. Malone, Social skills and learning disabilities: A meta-analysis of the literature, School Psychology Review, Vol. 21, No. 3, 427-443, 1992, https://doi.org/10.1080/02796015.1992.12085627

[14] S. Pavri \& R. Luftig, The social face of inclusive education: are students with learning disabilities really included in the classroom? Preventing School Failure: Alternative Education for Children and Youth, Vol. 45, No. 1, 8-14, 2001, https://doi.org/10.1080/10459880109599808

[15] A. Denham, S. Hatfield, N. Smethurst, E. Tan \& C. Tribe, The effect of social skills interventions in the primary school, Educational Psychology in Practice, Vol. 22, no.1, 33-51, 2006 https://doi.org/10.1080/02667360500512411

[16] H. Yoshikawa, T. S. Weisner, A. Kalil \& N. Way, Mixing qualitative and quantitative research in developmental science: Uses and methodological choices, Developmental Psychology, Vol. 44, No. 2, 344-354, 2008, https://doi.org/10.1037/0012-1649.44.2.344

[17] I. Vasileiadis \& M. Doikou - Avlidou, Enhancing social interaction of pupils with intellectual disabilities with their general education peers: the outcomes of an intervention programme, Journal of Research in Special Educational Needs, Vol. 18, No. 4, 267-277, 2018, https://doi.org/10.11 $11 / 1471-3802.12410$

[18] M. Lobrot, L' ecoute du desir. Paris: Retz, 1989

[19] I. Vasileiadis, S. Koutras \& I. Dimitriadou, The perceptions of Primary education teachers about inclusive education in the Greek educational system, European Journal of Education Studies, Vol. 8, No. 2, 12-31, 2021, http://dx.doi.org/10.46827/ejes.v8i2.3540

[20] H. Altrichter, P. Posch \& B. Somekh, Teachers investigate their work: an introduction to the methods of action research, London: Routledge, 1993

[21] J. M. Morse, M. Barrett, M. Mayan, K. Olson \& J. Spiers, Verification strategies for establishing reliability and validity in qualitative research, International Journal of Qualitative Methods, Vol. 1, 13-22, 2008, https://doi:10.4135/9781412963909.n230

[22] T. D. Lackaye \& M. Margalit, Comparisons of achievement, effort, and self-perceptions among students with learning disabilities and their peers from different achievement groups, Journal of learning disabilities, Vol. 39, No. 5, 432-446, 2006,https://doi.org/10.1177/0022219406039005 0501

[23] R. LaBarbera, Perceived Social Support and Self-Esteem in Adolescents with Learning Disabilities at a Private School, Learning Disabilities: A Contemporary Journal, Vol. 6, No. 1, 33-44, 2008

[24] R. Feldman, E. W.Carter, J.Asmus \& M. E. Brock, Presence, proximity, and peer interactions of adolescents with severe disabilities in general education classrooms, Exceptional 
Children, Vol. 82, No. 2, 192-208, 2016,https://doi.org/10. $1177 / 0014402915585481$

[25] R. S. Martínez, Social support in inclusive middle schools: Perceptions of youth with learning disabilities, Psychology in the Schools, Vol. 43, No2, 197-209, 2006, https://doi.org/10.1002/pits.20142

[26] S. Kravetz, M. Faust, S. Lipshitz \& S. Shalhav, LD, Interpsonal Understanding, and Social Behavior in the Classroom, Journal of learning disabilities, Vol. 32, No. 3, 248-255, 1999,https://doi.org/10.1177/0022219499032003 06

[27] N. L.Waldron, J. McLeskey \& D. Pacchiano, Giving teachers a voice: Teachers' perspectives regarding elementary inclusive school programs (ISP), Teacher Education and Special Education, Vol. 22, No. 3, 141-153, 1999, https://doi.org/10.1177/088840649902200302

[28] M. C. Ginevra, S. Santilli, I. Di Maggio \& L. Nota, 'The Good Actions': A kindergarten children intervention to promote social and inclusive relationships, European Journal of Developmental Psychology, Vol. 17, No. 6, 855-876, 2020,https://doi.org/10.1080/17405629.2020.173 3961

[29] L. J. Hall \& J. A. McGregor, A follow-up study of the peer relationships of children with disabilities in an inclusive school, The Journal of Special Education, Vol. 34, No. 3, 114-126, 2020,https://doi.org/10.1177/0022466900034003 01

[30] E. Emerson \& K. McVilly, Friendship activities of adults with intellectual disabilities in supported accommodation in Northern England, Journal of Applied Research in Intellectual Disabilities, Vol17, No. 3, 191-197, 2004, https://doi.org/10.1111/j.1468-3148.2004.00198.x
[31] G. Diaz-Garolera, M. Pallisera \& J. Fullana, Developing social skills to empower friendships: design and assessment of a social skills training programme, International Journal of Inclusive Education, 1-15, 2019, https://doi.org/10.1080 $/ 13603116.2019 .1625564$

[32] J. Mc Dougall, D. De wit, G. King, L. Miller \& S. Killip, High school-aged youths' attitudes toward their peers with disabilities: the role of school and student interpersonal factors, International Journal of Disability, Development and Education, Vol. 51, 287-313, 2004, https://doi.org/10.1080/1034912042000259242

[33] I. Vasileiadis., S. Koutras \& I. Dimitriadou, The perceptions of Primary education teachers about inclusive education in the Greek educational system. European Journal of Education Studies, Vol 8 No. 2, 12-31, 2021, http://dx.doi.org/10.46827/ejes.v8i2.3540

[34] A. Zoniou-Sideri, E. Deropoulou Derou, P. Karagianni \& I. Spandagou, Inclusive discourse in Greece: strong voices, weak policies, International Journal of Inclusive Education 2-3, 279-291, 2006, https://doi.org/10.1080/13603110500 256046

[35] G. Barbas, M. Birbili, P. Stagiopoulos \& S. Tzivinikou, A pilot study of factors affecting the process of integration in Greek nursery schools, European journal of special needs education, Vol. 21, No. 2, 217-226, 2006, https://doi.org/1 $0.1080 / 08856250600600950$

[36] I.Vasileiadis, S.Koutras \& P. Stagiopoulos, Changing the attitudes of high school students towards intellectual disabilities. The contribution of a social coexistence program, Journal of Research in Special Educational Needs, Vol 21, No 1, 49-62, 2021, http://dx.doi.org/10.1111/14713802.12498 